\title{
ARAŞTIRMA/RESEARCH
}

\section{Normal over rezervine sahip infertil hastalarda IVF-ICSI-ET sikluslarinda GnRH agonist uzun protokol ile GnRH antagonist protokolün karşılaştırılması}

Comparison between GnRH agonist long protocol and GnRH antagonist protocol in IVF-ICSI-ET cycles of normal ovarian reserve infertile patients

Önder Başeğmez ${ }^{1}$ İbrahim Ferhat Ürünsak², Ghanim Khatib², Cihan Çetin², Mete Sucu², Mehmet Özsürmeli2, Turan Çetin ${ }^{2}$

${ }^{1}$ Özel Adana Ortadoğu Hastanesi, Adana, Turkey

${ }^{2}$ Çukurova Üniversitesi Tıp Fakültesi, Kadın Hastalıkları ve Doğum Anabilim Dalı, Adana, Turkey

\begin{abstract}
Purpose: The aim of this study was to compare GnRH agonist long protocol and flexible multidose GnRH antagonist protocol for infertile patients with normal ovarian reserve in IVF-ICSI-ET cycles, on which controlled ovarian stimulation was carried out by using recombinant FSH.
\end{abstract}

Material and Methods: Medical files belonging to 1765 patients who were subjected to controlled ovarian stimulation by using recombinant FSH and afterwards to IVF-ICSI-ET were retrospectively analyzed. A total of 174 patients, 121 with GnRH agonist long protocol and 53 with flexible multidose GnRH antagonist protocol were included in the study. Stimulation periods, total doses of used FSH, obtained oocyte counts, fertilization rates, implantation rates, average values of hCG positive rates, clinic pregnancy and discharged newborn rates were compared between the two groups.

Results: Average of total stimulation time for $\mathrm{GnRH}$ antagonist protocol group was found to be $8.57 \pm 1.26$ days, while it was $9.47 \pm 1.56$ for the GnRG agonist group. HCG positive rates were $35.8 \%$ and $34.7 \%$ for the GnRH antagonist group and $\mathrm{GnRH}$ agonist group respectively. Rates of newborns discharged to home was $28.25 \%$ for $\mathrm{GnRH}$ antagonist protocol and $27.3 \%$ in th other.

Conclusion: Flexible multidose GnRH antagonist protocol provided shorter stimulation period and required less average total FSH dose when compared with the GnRH agonist long protocol. Besides flexible multidose $\mathrm{GnRH}$ antagonist protocol can be said to provide similar effectiveness with the GnRH agonist long protocol.

Key words: Infertile patients, IVF-ICSI-ET cycles, GnRH agonist long protocol
Amaç: Bu çalışmada normal over rezervine sahip infertil hastalarda rekombinant FSH kullanılarak kontrollü overyan stimülasyon yapılan IVF-ICSI-ET sikluslarında, GnRH agonist uzun protokol ile fleksible multidoz GnRH antagonist protokolü karşılaştırmayı amaçlanmıştır..

Gereç ve Yöntem: Çalışmamızda, kontrollü over stimülasyonu için rekombinant FSH kullanılmıs ve sonrasında IVF-ICSI-ET uygulanmış 1765 hastanın dosyalar1 retrospektif olarak taranarak kullanıldı. Belirlenen kriterlere uyan $121 \mathrm{GnRH}$ agonist uzun protokol ve 53 fleksible multidoz GnRH antagonist protokol uygulanan hasta olmak üzere, toplamda 174 hasta çalışmaya dahil edildi. İki grup arasındaki stimülasyon sürelerinin, FSH dozlarının, elde edilen oosit sayısı, fertilizasyon oranlarının, implantasyon oranlarının, hCG pozitiflik oranlarının, klinik gebelik oranlarının ve eve giden bebek oranlarının karşılaştırılması yapıldı.

Bulgular: Çalışmaya alınan hastalardan $\mathrm{GnRH}$ antagonist protokolde kullanilan ortalama toplam stimülasyon süresi $8.57 \pm 1.26$ gün iken, GnRH agonist grupta $9.47 \pm 1.56$ gün olarak bulundu. HCG pozitiflik oranları GnRH antagonist grupta \%35.8 iken, GnRH agonist grupta \%34.7 bulunmuştur. Eve giden bebek oranları GnRH antagonist protokolde \%28.25 iken, GnRH agonist long protokolde $\% 27.3$ bulunmuştur.

Sonuç: Fleksible multidoz GnRH antagonist protokolünde, stimülasyon süresi daha kısa ve FSH dozu daha azdır. Bununla beraber, GnRH agonist uzun protokol ile benzer başarı oranlarına sahip olduğu söylenebilir.

Anahtar kelimeler: İnfertil hastalar, IVF-ICSI-ET siklusları, GnRH agonist uzun protokol 


\section{GİRİ̧}

Infertilitenin toplumdaki sağlıklı çiftlerin \%10-15'ini ilgilendiren bir problem olduğu göz önüne alınırsa, yardımcı üreme tekniklerinin ne kadar çok çifte hitap ettiği daha iyi anlaşıllır ${ }^{1}$. Günümüzde invitro fertilizasyon (IVF) dünyadaki milyonlarca infertil çift için, umut ve ebeveyn olma hayallerini gerçekleştirme rüyaları ile eşanlamlı hale geldi. İlk tüp bebek olan Louise Brown'un 25 Temmuz 1978'deki doğumu, Dünya'da reprodüktif tıp dalı için bir devrim oldu. Nitekim 2010 yllında ilk tüp bebeği uygulamasını gerçekleştiren Dr. Edwards'a Nobel ödülü verildi.

Kontrollü over stimülasyonu (KOS) ile multiple folliküllerin ve bunun sonucunda çok sayıda oosit ve embriyoların elde edilebilmesi ile yardımcı üreme tekniklerin (YÜT) başarısını arttırılmaya amaçlanmıştır. KOS'un protokolü IVF uygulamalarının en önemli basamaklarından birisidir. İyi bir KOS protokolü IVF sonuçlarını olumlu olarak etkilemektedir. KOS sikluslarında \%20’lere varan prematür LH pikinin oluşması gebelik sonuçlarını olumsuz etkilediği görülmüştür. Gonadotropin salg1latıc1 hormon analoglarının $(\mathrm{GnRH})$ kullanıma girmesi ile prematür LH piki oluşumu engellenerek (\%2'lere düşmüş) gebelik oranları artmıştır ${ }^{2}$. Günümüzde GnRH analogları, gonadotropinlerle beraber sik reçete edilen tedavi ajanlarıdır. GnRH analog tedavi protokolleri arasında en sık kullanılanı GnRH agonist uzun protokoldür. $\mathrm{Bu}$ tedavi protokolü 2-3 haftalık bir desensitizasyon süresi gerektirdiğinden tedavi süresi ve ihtiyaç duyulan gonadotropin miktarı artar. Beraberinde overyan hiperstimülasyon sendromu riskini de barındırır. Hastalar desensitizasyon periyodunda, baş ağrısı, sıcak basması, vajinal kanama ve vajinal kuruluk gibi yan etkilere maruz kalabilir.

GnRH zincirinde aminoasitlerin multipl noktalarda başka moleküllerle yer değiştirmesi ile elde edilen bir diğer GnRH analogu da GnRH antagonistleridir. $\mathrm{GnRH}$ antagonistlerin reseptöre yüksek afinite ile bağlanıp endojen gonadotropin salınımını engelleyen olumlu farmakokinetik ve farmakodinamik özellikleri ile agonistlerin yerini alabilecekleri düşünülmüştür. Uzun desensitizasyon süresi gerektirmemesi, ilk flare up etkisinin olmamas1, k1sa sürede yeterli LH baskılaması sağlamas1, etkisinin doza bağımlı olması ve antagonist etkinin GnRH agonisti ile hızlıca geri döndürülebilmesi antagonistleri agonistlere üstün k1lan özellikleridir ${ }^{3,4}$. Yapılan çalışmalar tedavi süresinin ve kullanılan gonadotropin dozunun antagonist protokolde daha az olduğu yönündedir ${ }^{4,5}$.

IVF tedavisinde $\mathrm{GnRH}$ agonist veya $\mathrm{GnRH}$ antagonist kullanımına bağlı olarak endometriyal reseptivite, embriyo kalitesinde ve çeşitli serum hormon düzeylerinde değişiklikler olmaktadır ve bu değişimler IVF tedavi sonuçlarını etkilemektedir ${ }^{6,7}$. YÜT'de başarı özellikle yeterli bir KOS protokolüne bağlıdır. Gonadotropinlere yetersiz yanıt, siklus iptali, embriyo sayı ve kalitesinde azalma, düşük gebelik oranları ve bunların neticesinde çiftlerde ve doktorda stres ve hayal kırıklığı ile sonuçlanabilmektedir. Bu yüzden bu hastalara ideal KOS protokolünü belirlemek son derece önemli olmaktadır. İdeal KOS yöntemini belirlemek ancak literatüre geçecek bilimsel çalışmalarla mümkün olabilmektedir. $\mathrm{Bu}$ amaçla biz bu çalışma ile normal over rezervine sahip infertil hastalarda invitro fertilizasyon- intrasitoplazmik sperm injeksiyonuembriyo transferi (IVF-ICSI-ET) sikluslarında GnRH agonist long protokol ile fleksible multidoz $\mathrm{GnRH}$ antagonist protokollerini karşılaştırmayı amaçladik.

\section{GEREÇ VE YÖNTEM}

$\mathrm{Bu}$ çalışmanın yürütülmesi için $9 / 1$ nolu 31/05/2011 tarihli Çukurova Üniversitesi Tip Fakültesi Etik Kurulu'nun onayı alınmıştır. Çalışmamızda, Çukurova Üniversitesi Tıp Fakültesi Balcalı Hastanesi Kadın Hastalıkları ve Doğum Kliniğinin Yardımla Üreme Merkezinde 01.01.2007 01.03.2010 tarihleri arasında KOS için rekombinant FSH kullanılmış ve sonrasında IVF-ICSI-ET uygulanmış 1765 hastanın dosyaları retrospektif olarak taranarak kullanıldı. 649 hastaya rekombinant FSH ile GnRH agonist long protokol uygulanmış olduğu tespit edildi. 249 hastaya ise rekombinant FSH ile fleksible multidoz GnRH antagonist protokol tedavisi uygulandığı tespit edildi.

\section{Hasta seçimi}

$\mathrm{Bu}$ çalışma ile belirlenen kriterlere göre seçilen ve KOS için rekombinant FSH kullanarak GnRH agonist uzun protokol veya fleksible multidoz $\mathrm{GnRH}$ antagonist protokol uygulanmış hastalarda; retrospektif olarak iki protokol arasında kullanılan 
FSH toplam gün sayıları ve toplam FSH dozları, elde edilen oosit sayıları, elde edilen embriyo sayıları, human koryonik gonadotropin (hCG) pozitiflik oranlar1, klinik gebelik oranlar1, implantasyon oranlar1, abortus oranlar1, eve giden bebek oranlar1 açısından karşılaştırma yapmak amaçlanmıştır. Primer infertil, tubal patoloji veya açıklanamayan infertilite tanisı ile IVF ya da ICSI ile tedavi endikasyonu olan, ilk IVF-ICSI-ET denemesi olan, rekombinant FSH ile kontrollü overyan stimülasyon uygulanmış, yaşı $\leq 37$ olan, düzenli menstrüel siklusa sahip (25-35 gün), adetin 2-3. günlerinde bakilan FSH $<10$ olan, TSH ve prolaktin değerleri normal sinırlarda olan ve embriyo transferi sonrası luteal faz desteği alan hastalar çalışma popülasyonunu oluşturdu. Diğer taraftan, histerosalpingografi ya da histeroskopi ile endometriyal kavitenin değerlendirilmesi sonucunda polip, submuköz myom, septum uteri gibi yer kaplayan lezyon tespit edilen, over cerrahisi geçirmiş olan, tek overi bulunan, daha önce endometriyozis tanısı veya tedavisi almış olan, polikistik over sendromu tanısı almış olan, eşinde erkek faktör tespit edilen ve sekonder infertilite tanısı alan hastalar dişlandi. Belirlenen bu kriterlere uyan 121 rekombinant FSH ile GnRH agonist long protokol ile KOS uygulanan hasta ve 53 rekombinant FSH ile fleksible multidoz $\mathrm{GnRH}$ antagonist protokol ile KOS uygulanan hasta olmak üzere, toplamda 174 hasta çalışmaya dahil edildi.

\section{Parametreler}

Seçilen hastaların dosyalarından yaşları, infertilite süreleri, infertilite sebepleri, obstetrik ve jinekolojik özgeçmişleri, menstrüel siklus düzenleri, boy, ağırlık ve vücut kitle indeksi (VKI) (ağırlık/boy2) bilgileri, adetin 2-3. günleri bak1lan FSH, E2, LH bilgileri, kullanılan toplam FSH stimülasyon süreleri ve toplam FSH dozları, elde edilen follikül sayıları, hCG uygulama günündeki östradiol seviyeleri, hCG günü bakılan endometriyal kalınlıkları, total oosit sayılar1, metafaz 2 oosit sayıları, fertilize oosit sayıları, toplam elde edilen embriyo sayıları, transfer edilen embriyo sayıları, hCG pozitifliği, klinik gebelik varlığı, elde edilen gebelik kesesi sayıları, çoğul gebelik varlığı, abortus varlığ1, eve giden bebek sayılarına ait bilgiler tarand1 ve kaydedildi. Bu parametrelere göre iki grup arasındaki farklar araştırıldı. Fertilizasyon oranı; (fertilize oosit say1s1/ICSI uygulanan oosit say1s1 $x$ 100) ve implantasyon oranı; (oluşan gebelik kesesi sayıs1/transfer edilen embriyo sayıs1 x100) şeklinde hesaplandi.

\section{İstatistiksel analiz}

Verilerin istatistiksel analizinde SPSS 17.0 paket programı kullanıldı. Sürekli değişkenlerin ikili karşılaştırması için t-testi veya Mann Whitney U testi kullanıldı. Kesikli (binary) değişkenler arasındaki ilişki, bağımsız olup olmadıkları veya oranlarının iki protokol grubunda dağılımlarının homojen olup olmadığ1 Ki-kare analizi ile araştırıldı. Başarı oranını etkileyen faktörler multivariate analiz yöntemi olan lojistik regresyon modeli ile araştırıldı. Modele; yaş, VKİ, infertilite süresi, infertilite nedeni ve uygulanan protokol dahil edildi. Her birisinin diğerlerinden bağımsız etkisi araştırıldı. Tüm testlerde $\mathrm{p}$ değerinin $<0,05$ olduğu durumlar istatistiksel olarak anlamlı kabul edildi.

\section{BULGULAR}

Belirlenen kriterlere göre çalışmaya dahil edilen hastalar 2 grup halinde incelendi. Grup 1'de 53 hasta (fleksible multidoz GnRH antagonist protokol uygulanan grup) ve grup 2'de 121 hasta (GnRH agonist long protokol uygulanan grup) çalışmaya dahil edildi.

Hastalara ait grupların temel karakteristik özellikleri Tablo 1'de verilmiştir. Grupların temel karakteristik özellikleri incelendiğinde; kadın yaşı, vücut kitle indeksi, siklusun 3. günü FSH, E2 ve LH değerleri bakımından iki grup arasında istatistiksel olarak anlamlı fark bulunmamıştır ( $\mathrm{p}>0.05)$.

Grupların tedavi karakteristikleri, follikül gelişimi ve hormon düzeyleri ile ilgili veriler Tablo 2'de verilmiştir. GnRH antagonist protokolde kullanılan ortalama toplam stimülasyon süresi $8.57 \pm 1.26$ iken, $\mathrm{GnRH}$ agonist grupta $9.47 \pm 1.56$ olarak bulundu. Uygulanan protokole göre kullanilan ortalama toplam stimülasyon süreleri bakımından iki grup istatistiksel olarak anlamlı derecede farklı bulundu $(\mathrm{p}<0.001)$. GnRH antagonist protokolde kullanilan ortalama toplam FSH dozu $1368.4 \pm 271.97$ iken, GnRH agonist grupta $1474.38 \pm 283.53$ olarak bulundu. Uygulanan protokole göre kullanılan ortalama toplam FSH dozları bakımından iki grup istatistiksel olarak anlamlı derecede farklı bulundu $(p=0.023)$. HCG gününde elde edilen ortalama toplam $17 \mathrm{~mm}$ ve üzeri follikül sayıları incelemesinde iki grup arasında istatistiksel olarak anlamlı fark tespit edildi ( $p=0.007)(p<0.05)$. HCG gününde elde edilen ortalama toplam 14-16 mm 
follikül sayıları incelemesinde iki grup arasında istatistiksel olarak anlamlı fark tespit edildi $(p=0.022)$. HCG günü ortalama östradiol seviyeleri

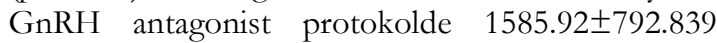
iken, GnRH agonist long protokolde $2029.29 \pm$ 1153.05 bulunmuştur. Uygulanan protokole göre gruplar hCG günü E2 seviyesi bakımından istatistiksel olarak anlamlı derecede farklı idi $(\mathrm{p}=0.012)$. hCG günü bakılan ortalama endometriyal kalınlık GnRH antagonist protokolde $11.32 \pm 1.20$ iken, GnRH agonist long protokolde $11.79 \pm 1.51$ bulunmuştur. Sonuç olarak iki grup arasında endometriyal kalınlık değerlendirmesinde istatistiksel olarak anlamlı fark tespit edilmedi $(\mathrm{p}=0.05)$.

Hastalara ait grupların sonuç parametreleri ile ilgili veriler Tablo 3'de verilmiştir. Tedavi sonrası elde edilen ortalama toplam oosit say1lar1 GnRH antagonist protokolde $6.49 \pm 3.97$ iken, GnRH agonist long protokolde $8.15 \pm 4.37$ bulunmuştur. Uygulanan protokole göre iki grup arasinda istatistiksel olarak anlaml fark mevcut idi ( $\mathrm{p}=$ 0.019). İki grup arasinda tedavi sonrası elde edilen ortalama toplam metafaz 2 oosit sayıları, ortalama toplam fertilize oosit sayıları, 3. gün elde edilen ortalama toplam embriyo sayları ve transfer edilen ortalama toplam embriyo sayları bakımından istatistiksel olarak anlamlı fark tespit edilmedi ( $\mathrm{p}>$ 0.05). Tedavi sonras1 fertilizasyon oranlar1 GnRH antagonist protokolde \%70.7 iken, GnRH agonist long protokolde $\% 60.5$ olarak bulunmuştur. Uygulanan protokole göre gruplar fertilizasyon oranları bakımından anlamlı derecede farklı bulundu $(\mathrm{p}=0.004)$. İmplantasyon oranları GnRH antagonist protokolde \%16.34 iken, $\mathrm{GnRH}$ agonist long protokolde \%15.78 bulunmuştur. Uygulanan protokole göre gruplar arasinda implantasyon oranları bakımından istatistiksel olarak anlamlı fark yoktu $(p=0.89)$. HCG pozitiflik oranları GnRH antagonist grupta \%35.8 iken, GnRH agonist grupta \%34.7 bulunmuştur. HCG pozitifliği antagonist grupta biraz daha fazla olmak ile birlikte istatistiksel olarak fark anlamsızdır $(\mathrm{p}=0.508)$. İki grup arasında klinik gebelik oranları, çoğul gebelik oranları, abortus oranları bakımından istatistiksel anlamlı fark tespit edilmedi $(\mathrm{p}>0.05)$. Eve giden bebek oranlar1 GnRH antagonist protokolde \%28.25 iken, GnRH agonist long protokolde \%27.3 bulunmuştur. Sonuç olarak iki grup arasında eve giden bebek oranları bakımindan istatistiksel olarak anlamlı fark yoktu $(\mathrm{p}=0.503)$.

Tablo 1. Grupların temel karakteristik özellikleri ile ilgili veriler

\begin{tabular}{|l|c|c|c|}
\hline Değişken & $\begin{array}{c}\text { Grup I } \\
\text { (Antagonist Protokol) } \\
\text { Ortalama / Std. Sapma }\end{array}$ & $\begin{array}{c}\text { Grup II } \\
\text { (Long Protokol) } \\
\text { Ortalama / Std. Sapma }\end{array}$ & $\begin{array}{c}\text { P } \\
\text { değeri }\end{array}$ \\
\hline Kadın yaş1 (yll) & $29.74 \pm 4.01$ & $29.08 \pm 3.23$ & 0.26 \\
\hline Vücut kitle indeksi (kg/m2) & $27.17 \pm 4.77$ & $25.96 \pm 5.06$ & 0.14 \\
\hline İnfertilite süresi (y1l) & $5.15 \pm 2.73$ & $3.91 \pm 1.39$ & $<0.01$ \\
\hline Siklusun 3. günü FSH değerleri & $6.26 \pm 1.44$ & $6.45 \pm 1.58$ & 0.45 \\
\hline Siklusun 3. günü E2 değerleri & $45.44 \pm 17.45$ & $49.17 \pm 22.53$ & 0.29 \\
\hline Siklusun 3. günü LH değerleri & $5.89 \pm 6.30$ & $4.73 \pm 1.71$ & 0.06 \\
\hline
\end{tabular}

Tablo 2. Gruplar arasındaki tedavi karakteristikleri, follikül gelişimi ve hormon düzeyleri ile ilgili veriler

\begin{tabular}{|l|c|c|c|}
\hline Değişken & $\begin{array}{c}\text { Grup I } \\
\text { (Antagonist Protokol) } \\
\text { Ortalama / Std.Sapma }\end{array}$ & $\begin{array}{c}\text { Grup II } \\
\text { (Long Protokol) } \\
\text { Ortalama / Std.Sapma }\end{array}$ & P değeri \\
\hline Stimülasyon süresi (gün) & $\mathbf{8 . 5 7} \pm 1.26$ & $\mathbf{9 . 7 4} \pm 1.56$ & $<0.001$ \\
\hline Kullanılan toplam FSH dozu(IU) & $\mathbf{1 3 6 8 . 4 \pm 2 7 1 . 9 7}$ & $\mathbf{1 4 7 4 . 3 8 \pm 2 8 3 . 5 3}$ & $\mathbf{0 . 0 2 3}$ \\
\hline $\begin{array}{l}\text { hCG gününde 17 mm ve üstü follikül } \\
\text { sayıs }\end{array}$ & $4.36 \pm 1.50$ & $\mathbf{5 . 5 2} \pm 1.70$ & $\mathbf{0 . 0 0 7}$ \\
\hline hCG gününde14-16 mm follikül sayıs1 & $\mathbf{5 . 5 8} \pm 2.40$ & $\mathbf{6 . 8 1} \pm 2.20$ & $\mathbf{0 . 0 2 2}$ \\
\hline $\begin{array}{l}\text { hCG uygulamas1 sırasındaki kan E2 } \\
\text { seviyesi (pg/mL) }\end{array}$ & $\mathbf{1 5 8 5 . 9 2 \pm 7 9 2 . 8 3 9}$ & $\mathbf{2 0 2 9 . 2 9 \pm 1 1 5 3 . 0 5}$ & $\mathbf{0 . 0 1 2}$ \\
\hline $\begin{array}{l}\text { hCG uygulamas1 sırasindaki } \\
\text { endometriyal kalınlık (mm) }\end{array}$ & $11.32 \pm 1.20$ & $11.79 \pm 1.51$ & $\mathbf{0 . 0 5}$ \\
\hline
\end{tabular}


Tablo 3. Sonuç parametreleri ile ilgili veriler

\begin{tabular}{|l|c|c|c|}
\hline Değişken & $\begin{array}{c}\text { Grup I } \\
\text { (Antagonist Protokol) } \\
\text { Ortalama/Std. Sapma }\end{array}$ & $\begin{array}{c}\text { Grup II } \\
\text { (Long Protokol) } \\
\text { Ortalama/Std. Sapma }\end{array}$ & P değeri \\
\hline Toplanan oosit sayıs1 & $6.49 \pm 3.97$ & $8.15 \pm 4.37$ & 0.019 \\
\hline MII oosit sayıs1 & $5.4 \pm 3.14$ & $6.45 \pm 3.45$ & 0.060 \\
\hline Fertilize oosit sayıs1 & $4.43 \pm 3.15$ & $4.58 \pm 2.83$ & 0.765 \\
\hline 3. gün embriyo sayıs1 & $4.43 \pm 3.15$ & $4.56 \pm 2.83$ & 0.791 \\
\hline Embriyo transfer sayıs1 & $2.47 \pm 0.77$ & $2.5 \pm 0.95$ & 0.865 \\
\hline Fertilizasyon oran1 (\%) & 70.7 & 60.52 & 0.004 \\
\hline hCG pozitif gebelik oranı (\%) & 35.8 & 34.7 & 0.508 \\
\hline Klinik gebelik oranı (\%) & 32.1 & 32.2 & 0.565 \\
\hline Eve giden bebek oranı (\%) & 28.25 & 27.3 & 0.530 \\
\hline İmplantasyon oranı (\%) & 16.34 & 15.78 & 0.89 \\
\hline Çoğul Gebelik Oranı (\%) & 9.4 & 8.3 & 0.503 \\
\hline Abortus oranı (\%) & 7.5 & 7.4 & 0.600 \\
\hline
\end{tabular}

\section{TARTIŞMA}

IVF/ICSI uygulamalarında ilk basamak olarak folliküler gelişimi sağlamak için kontrollü overyan stimülasyon gerekir. KOS'da human menopozal gonadotropin (hMG), üriner FSH veya ultra saflaştırılmış üriner FSH'lar, rekombinant gonadotropinler (rFSH, rLH) gerekli stimülasyonu sağlamak için yaygın olarak kullanılmaktadır. Ancak KOS'da erken lüteinize edici hormon piki ve erken ovulasyon siklusun iptaline neden olabilir. Tüm IVF/ICSI sikluslarında GnRH agonisti veya antagonisti kullanilmaz ise, \%20 spontan ovulasyon meydana gelmektedir. Bu \%20'lere varan prematür endojen LH artışı, GnRH analoglarının kullanılmaya başlanması ile $\% 2$ 'ye düşürülmüştür ${ }^{2}$.

Normal over rezervine sahip infertil hastalarda $\mathrm{GnRH}$ antagonist protokol ile $\mathrm{GnRH}$ agonist long protokolü karşılaştıran Hohmann ve arkadaşları, prospektif randomize çalışmalarında, iki protokol arasinda kullanilan gonadotropin stimülasyon gün say1s1 antagonist protokolde daha kisa ve kullanilan toplam gonadotropin dozlar1 $\mathrm{GnRH}$ antagonist protokolde daha az bulmuşlardır $(\mathrm{p}<0.01)^{8}$. Benzer şekilde, Albano ve ark.'nın yaptıkları çalışmada $\mathrm{GnRH}$ antagonist grubu GnRH agonist gruba k1yasla daha kısa stimülasyon süresine sahip olduğu ve daha az total doz gonadotropin gerektirdiği görülmüştür ${ }^{9}$. Kolibianakis ve ark.'nın yayımladığı meta-analizde ise, GnRH antagonist grupta GnRH agonist gruba kiyasla stimülasyon gün sayısı daha az bulunmuş, Fakat kullanılan toplam FSH dozu bakımından iki grup arasında fark bulunmamıştır ${ }^{10}$. Bizim çalışmamızın sonuçları değerlendirildiğinde,
GnRH antagonist protokol uygulanan hastaların stimülasyon süresi, GnRH agonist protokol grubuna göre istatistiksel olarak daha kısa idi $(\mathrm{p}<0.001)$. Kullanılan total FSH dozlarının değerlendirmesinde ise, ortalama toplam FSH dozu GnRH antagonist grupta GnRH agonist gruba kiyasla istatistiksel olarak anlamlı oranda daha az bulundu $(\mathrm{p}=0.023)$.

Hohmann ve ark. yaptıkları çalışmalarında normal over rezervli infertil hastalarda GnRH antagonist protokolü ile $\mathrm{GnRH}$ agonist protokolünün, elde edilen total follikül ve oosit sayılarını benzer bulmuşlardır $(\mathrm{p}>0.05)^{8}$. Ludwig'in meta-analizinde antagonist grubunda ortalama 2.6 oosit daha az toplandığ1 belirtilmektedir $(\mathrm{p}<0.05)^{11}$. Kolibianakis ve ark.'nın yayımladığı meta-analizde GnRH antagonist gruptan toplanan oosit sayıs1, GnRH agonist gruptan toplanan oosit sayısindan ististiksel olarak anlamlı derecede daha az bulunmuştur ${ }^{10}$. Öktem ve ark.'nın normal over yanıtlı IVF hastalarında yaptıkları çalışmalarında Elde edilen oosit say1lar1 bakımindan da GnRH antagonist protokol GnRH agonist protokole göre anlamlı oranda daha az olarak bulmuşlardır $(\mathrm{p}<0.01)^{12}$. Grow ve Ark'nin iyi prognozlu hastalarda ve tekrarlayan IVF başarısızlığ1 olan hastalar üzerinde yaptıkları analizde $\mathrm{GnRH}$ agonist protokolde $\mathrm{GnRH}$ antagonist protokole göre daha fazla oosit elde edildiği, implantasyon oranının arttığ1 ve transfer başına daha fazla canlı doğum elde edildiği bildirmişlerdir ${ }^{13}$. Çalışmamızda GnRH antagonist protokol uygulanan grup için 14-16 mm follikül sayıları ve $\geq 17 \mathrm{~mm}$ follikül sayıları $\mathrm{GnRH}$ agonist gruba göre anlamlı olarak daha azdı. Buna rağmen elde edilen metafaz 2 oosit sayları, fertilize oosit 
sayılar1, 3. gün elde edilen toplam embriyo sayıları ve transfer edilen embriyo sayıları bakımından iki grup arasında istatistiksel olarak anlamlı fark tespit edilmedi. $\mathrm{Bu}$ verilerden elde edilen sonuç $\mathrm{GnRH}$ antagonist protokol uygulanan grupta $\mathrm{GnRH}$ agonist long protokol uygulanan gruba kiyasla kullanilan gonadotropin süresi ve toplam dozunun daha az olmas1 ile birlikte elde edilen total oosit sayıs daha az olmasına rağmen kaliteli oosit sayıları, fertilize oosit sayılar1, toplam embriyo sayılar1 ve transfer edilen toplam embriyo sayıları bakımından iki grubun benzer olduğudur.

Ludwig ve ekibi tarafindan yapılan meta analiz sonucunda, hCG pozitif gebelik oranı ve devam eden gebelik oranında, iki protokol arasında istatistiksel bir fark bulunmamıstır $(\mathrm{p}>0.059)^{11}$. Diğer bir meta analiz Cochrane Kütüphanesi tarafından yayımlanmıştır ve gerçek randomizasyon içeren beş randomize kontrollü çalışma içermektedir. Ana sonuç ölçümü hCG pozitif gebelik oranı olan bu çalışma sonucu, GnRH antagonist kullanıldığında, GnRH agoniste kıyasla belirgin ölçüde daha az hCG pozitif gebelik oranına rastlanılmıştır ${ }^{14}$. Üçüncü bir meta analiz ise, on dört randomize kontrollü çalışma ve konferanslarda sunulan randomize kontrollü çalışmaların özetlerini içermektedir. İki protokol arasında hCG pozitif gebelik oranında bir fark bulunmamıştır ${ }^{15}$. Albano ve ark.'nın çalışmasında iki protokol arasında klinik gebelik oranları bakımından fark bulunmamaıştır 9 . Kolibianakis ve ark.'nın yayımladığı sonuç ölçümü olarak canlı doğum oranını kabul eden meta analiz yirmi iki randomize kontrollü çalışmayı içermektedir. İki protokol arasında canlı doğum oranları bakımından istatistiksel olarak anlamlı fark bulmamışlardır ${ }^{10}$. Öktem ve ark. normal over yanıtlı IVF hastalarında yaptıkları çalışmalarında klinik gebelik oranları iki grup için benzerdir. Ayrıca, iki grup arasında implantasyon oranları bakımından fark saptanmamıştır ${ }^{12}$. Bizim çalışmamızın gebelik sonuçlarının değerlendirmesinde hCG pozitiflik oranları GnRH antagonist grubunda \%35.8, GnRH agonist grubunda \%34.7 bulunmuştur ve iki grup arasında hCG pozitifliği oranları bakımından istatiksel anlamlı fark tespit edilmemiştir. Çalışmamızın klinik gebelik oranları incelemesinde de iki grup arasında istatistiksel anlamlı fark saptanmamıştır. Gruplar arasındaki klinik abortus oranlarına bakıldığında, iki grup klinik abortus oranları bakımından benzerlik göstermektedir. Çalışmamızı eve giden bebek oranları bakımından değerlendirecek olursak GnRH antagonist grupta
$\% 28.25$, GnRH agonist grupta \%27.3 olup iki grup arasinda eve giden bebek oranları benzer bulunmuştur. Çelik ve Ark'nın normal over rezervine sahip hastalar ile yaptıkları çalışmalarında, bu iki farklı protokolde klinik gebelik oranları farklı bulunmamıştır ${ }^{16}$. Uludağ ve ark.'nın zayıf over rezervli hastalar ile yaptıkları benzer çalışmada da stimülasyon parametreleri ve klinik gebelik oranları açısından fark olmadığı sonuncuna varılmıştır ${ }^{17}$. Obez hastalarla yürütülen bir çalışmada ise, siklus uzunluğu, elde edilen oosit sayısı ve transfer edilen embriyo sayısı farklı bulunmamıştır. Fakat klinik gebelik oranı, normal VKİ olan hastalardan daha yüksek bulunmuştur ${ }^{18}$. Bizim çalışmamızda hasta gruplarında VKİ açısından fark bulunmamıştır.

Sonuç olarak, bu çalışmada normal over rezervli infertil hastalarda kontrollü overyan stimülasyon yapılan IVF-ICSI-ET sikluslarında, GnRH agonist uzun protokol ile fleksible multidoz GnRH antagonist protokolü karşılaştırdık ve çalışmamızın sonucu literatür ile uyumlu olarak, fleksible multidoz GnRH antagonist protokolünde, stimülasyon süresi daha kisa ve FSH dozu daha az olmakla beraber, GnRH agonist uzun protokol ile benzer etkinlikte ve başarı oranlarına sahip olduğu söylenebilir. Dolayisiyla normal over rezervli infertil hastalarda, daha düşük maliyeti nedeniyle, fleksible multidoz GnRH antagonist protokolünü kullanmak, akılc1 olabilir. Yine de, çalışmaya alınan hasta sayısının nispeten az ve çalışmanın retrospektif karakterde olması, çalışmanın dezavantajları olup kesin bir yorum yapmamızı engellemektedir. Bu yüzden, olgu sayısının fazla olduğu randomize prospektif kontrollü çalışmalara ihtiyaç vardır.

\section{KAYNAKLAR}

1. Barbieri RL. Female infertility. In Strauss FJ, Barbieri RL (eds), Reproductive endocrinology. Pensylvania:Elsevier Inc., 5th ed, 2004;633-68.

2. Garcia-Velasco JA, Isaza V, Vdal C. Human ovarian steroid secretion in vivo: effects of GnRH agonist versus antagonist (cetrorelix). Hum Reprod. 2001;16:2533-9.

3. Shapiro DB. An overview of $\mathrm{GnRH}$ antagonists in infertility treatments. Introduction. Fertil Steril. 2003;80(1):S1-7.

4. Olivennes F, Cunha-Filho JS, Fanchin R. The use of GnRH antagonists in ovarian hyperstimulation. Hum Reprod Update. 2002;8(3):279-90.

5. Hugues JN. Ovarian stimulation for assisted reproductive technologies. In Vayana E, Rowe PS, Griffin PD (eds), Current practices and controversies 
in assisted reproduction: report of a WHO meeting. Geneva: WHO, 2002;102-25.

6. Xiao JS, Su CM, Zeng XT. Comparisons of GnRH antagonist versus $\mathrm{GnRH}$ agonist protocol in supposed normal ovarian responders undergoing IVF: a systematic review and meta-analysis. PLoS One. 2014;9:e106854.

7. Choi MH, Lee SH, Kim HO, Cha SH, Kim JY, Yang $\mathrm{KM}$, et al. Comparison of assisted reproductive technology outcomes in infertile women with polycystic ovary syndrome: In vitro maturation, $\mathrm{GnRH}$ agonist, and GnRH antagonist cycles. Clin Exp Reprod Med. 2012;39:166-71.

8. Hohmann FP, Macklon NS, Fauser BC. A randomized comparison of two ovarian stimulation protocols with gonadotropinreleasing hormone (GnRH) antagonist cotreatment for in vitro fertilization commencing recombinant folliclestimulating hormone on cycle day 2 or 5 with the standard long GnRH agonist protocol. J Clin Endocrinol Metab. 2003;88,166-73.

9. Albano C, Felberbaum RE, Smitz J, RiethmullerWinzen $\mathrm{H}$, Engel J, Diedrich $\mathrm{K}$ et al. Ovarian stimulation with HMG: results of a prospective randomized phase III European study comparing the luteinizing hormone-releasing hormone (LHRH)antagonist cetrorelix and the 58 LHRH-agonist buserelin. European Cetrorelix Study Group. Hum Reprod. 2000;15:526-33.

10. Kolibianakis EM, Collins J, Tarlatzis BC. Among patients treated for IVF with gonadotrophins and $\mathrm{GnRH}$ analogues, is the probability of live birth dependent on the type of analogue used? A systematic review and meta-analysis. Hum Reprod Update. 2006;12:651-71.

11. Ludwig M, Katalinic A, Diedrich K. Use of GnRH antagonists in ovarian stimulation for assisted reproductive technologies compared to the long protocol. Meta-analysis. Arch Gynecol Obstet. 2001:265:175-82.

12. Öktem $\mathrm{O}$, Mercan $\mathrm{R}$, Balaban B, Urman B. Comparison of IVF outcomes between GnRH antagonist and $\mathrm{GnRH}$ agonist long protocols in normo responder IVF patients. Fertil Steril. 2010;94:S260.

13. Grow D, Kawwass JF, Kulkarni AD, Durant T, Jamieson DJ, Macaluso M. GnRH agonist and GnRH antagonist protocols: comparison of outcomes among good-prognosis patients using national surveillance data. Reprod Biomed Online. 2014;29:299-304.

14. Al-Inany $\mathrm{H}$, Aboulghar M. GnRH antagonist in assisted reproduction: a Cochrane review. Hum Reprod. 2002;17:874-9.

15. Daya S. A comparison of clinical pregnancy rates in the efficacy evaluation of $\mathrm{GnRH}$ agonist versus antagonist use for assisted reproduction - a metaanalysis using an intention to treat approach. Gynaecol Endocrinol. 2003:44-55.

16. Çelik S, Gürbüz B, Çelik DC, Purisa S. Comparison of GnRH agonist long and antagonist protocols in the normoresponder patient undergoing controlled ovarian hyperstimulation / intracytoplasmic sperm injection in terms of clinical outcome. İstanbul Med J. 2013;14:234-7.

17. Uludağ S, Kutuk MS, Dolanbay M, Altun O, Ozgun MT, Aygen E et al. Comparison of GnRH-agonist microdose flare-up protocol and flexible multiple dose antagonistic protocol in poor responder patients undergoing intracytoplasmic sperm injection cycle. Erciyes Med J. 2013;35:52-5.

18. Marci R, Lisi F, Soave I, Lo Monte G, Patella A, Caserta $\mathrm{D}$, et al. Ovarian stimulation in women with high and normal body mass index: GnRH agonist versus GnRH antagonist. Gynecol Endocrinol. 2012;28:792-5. 